\section{Sequential release of lysosomal inflammation mediators and chemiluminescence response of stimulated polymorphonuclear leukocytes *}

\author{
M. Jochum ${ }^{1}$ and A. Dwenger ${ }^{2}$ \\ ${ }^{1}$ Abteilung für Klinische Chemie und Klinische Biochemie, \\ Chirurgische Klinik Innenstadt der Universität München, \\ Nußbaumstr. 20, D-8000 München 2, \\ Federal Republic of Germany \\ 2 Abteilung für Klinische Biochemie, Medizinische Hochschule \\ Hannover, Konstanty-Gutschow-Straße 8, \\ D-3000 Hannover 61, Federal Republic of Germany
}

\section{Sequentielle Freisetzung lysosomaler Entzündungsmediatoren und Chemiluminescenz-Antwort stimulierter polymorphkerniger Leukocyten}

\section{Introduction}

The response of polymorphonuciear leukocytes (PMNL) to appropriate stimuli is manifold: production of chemoattractants, sequential discharge of lysosomal proteins into the phagolysosome and to the external environment, activation of the respiratory burst etc. [1,2]. Oxygen radicals generated during PMNL stimulation and lysosomal constituents are primarily involved in the bactericidal activities of the phagocytes, but they may also mediate inflammatory reactions, especially when liberated extracellularly [3].

The measurement of chemiluminescence $(\mathrm{CL})$ arising from the combined oxidizing properties of oxygen radicals is widely used as a functional assay of phagocytic activity [4]. Applying luminol as a light amplifier even trace amounts of activated oxygen species are detectable.

Recent availability of sensitive methods for the determination of lysosomal proteins enabled us to study the extracellular release kinetics of azurophilic (elastase, myeloperoxidase) and specific (lactoferrin) granule constituents additionally to the photon emission of PMN leukocytes in response to particulate (zymosan) and soluble (endotoxin) stimuli.

\section{Methods}

Isolation of $P M N L$. Polymorphonuclear leukocytes from normal donors were isolated by the use of a discontinuous twostep Percoll gradient according to [5], resuspended to $8 \cdot 10^{6}$ cells/ml MEM Dulbecco buffer solution (Boehringer, Mannheim, FRG) and kept at room temperature until use (within one hour).

Stimulation experiments. Stimulators were applied at final concentrations previously shown to give a maximal CL response: $3.5 \mathrm{mg} / \mathrm{ml}$ non-opsonized zymosan $\mathrm{A}$ and $44 \mu \mathrm{g} / \mathrm{ml}$ endotoxin (lipopolysaccharide from E. coli No. 055:B5), respectively; both substances were purchased from Sigma Chemical Co., St. Louis, MO, USA). The reaction mixture (prewarmed to $37^{\circ} \mathrm{C}$ ) for each set of experiments was composed of $5.80 \mathrm{ml}$ MEM buffer solution, $0.15 \mathrm{ml}$ luminol solution, $1.40 \mathrm{ml}$ citrated normal plasma and $0.30 \mathrm{ml}$ stimulator. The reaction was started by the addition of $0.35 \mathrm{ml}$ PMNL suspension. One aliquot $(570 \mu \mathrm{l})$ was immediately centrifuged as described below (time 0 ). Thereafter six CL polystyrene vials were filled quickly with $570 \mu \mathrm{l}$ each of the gently agitated mixture and the luminol enhanced CL (peak maximum counts/min) was determined simultaneously in the six channel Biolumat LB 9505 (Laboratorium Prof. Dr. Berthold, Wildbad, FRG) at $37^{\circ} \mathrm{C}$ according to [5]. At the times indicated $(5,10,20,30,45$, and

\footnotetext{
" Supported by the "Deutsche Forschungsgemeinschaft", project II B 6 and SFB 207/C 1
}

$60 \mathrm{~min}$ after onset), the content of one vial each was transferred to an Eppendorf tube and the incubation reaction was stopped by centrifugation at $12,000 \times g$ for $15 \mathrm{~s}$. The supernatants were frozen in liquid nitrogen and kept at $-70^{\circ} \mathrm{C}$ until aliquots were assayed for the released granule constituents. A set of analogous reaction mixtures without stimuli served as blanks. Cell disintegration was monitored by lactate dehydrogenase release (test combination "LDH opt.", Boehringer, Mannheim, FRG), that did not exceed $2 \%$ with any stimuli used.

Lysis of PMNL. In order to measure the total content of the granule constituents additionally 1 volume of the stimulated granulocyte suspension (at time 0 ) was diluted with 1 volume of lysing mixture (1.5 g digitonin and $1 \mathrm{~g} \mathrm{NP} 40$ in $100 \mathrm{ml}$ of water), sonicated for $10 \mathrm{~s}$ in ice and frozen at $-70^{\circ} \mathrm{C}$. Before determination the rethawed samples were sonicated again for $10 \mathrm{~s}$.

Measurement of lysosomal proteins. The immunological determination of the elastase concentration was performed with the enzyme immuno assay test combination "PMN Elastase" (E. Merck, Darmstadt, FRG). Thereby only elastase complexed with $\alpha_{1}$-proteinase inhibitor is detected. To achieve complex formation normal plasma has been added to the incubation mixture (see above). The concentrations of myeloperoxidase and lactoferrin were determined with newly developed sandwich enzyme-linked immuno assays (see Neumann et al. and Rautenberg et al., this issue).

Calculation procedures. After subtractive correction for the corresponding blanks the amount of each granule protein discharged to the supernatant was calculated in two different ways: (i) protein amount released per min as the percentage of the total concentration available in the lysed sample (Fig. 1a,c) or (ii) protein amount in $\mu \mathrm{g} / \mathrm{ml}$ supernatant at the times indicated (Fig. 1b,d).

\section{Results}

Zymosan, a model substance for particulate stimuli induced the maximal release of elastase and lactoferrin nearly simultaneously in height (ca. $4 \% / \mathrm{min}$ ) as well as in velocity (at $8.5 \mathrm{~min}$ ). Compared with this, maximal discharge of myeloperoxidase and photon emission per min was delayed to $15 \mathrm{~min}$ after onset of stimulation (Fig. 1a). Figure $1 \mathrm{~b}$ additionally demonstrates that the lactoferrin release had stopped at $30 \mathrm{~min}$ (reaching $65 \%$ of the total available amount), whereas the discharge of elastase and myeloperoxidase still continued to $45 \mathrm{~min}$ ( $85 \%$ of total) and $60 \mathrm{~min}(65 \%$ of total), respectively. Likewise, photon emission had not reached its end point at 60 min experimental time. In contrast, endotoxin caused a preferential release of lactoferrin with a maximal velocity at $15 \mathrm{~min}$ after adding the soluble stimulus. Discharge of elastase and myeloperoxidase as well as the generation of $\mathrm{CL}$ was significantly retarded both in maximal velocity (at $25 \mathrm{~min}$, Fig. 1c) and amount (Fig. 1d). Lactoferrin release ceased at 25 min (reaching $15 \%$ of total) after starting the experiment, whereas elastase, myeloperoxidase and photon emission still continued to the end of the incubation time though at a very low level ( 5 and $2.5 \%$ of total elastase and myeloperoxidase amounts, respectively, at $60 \mathrm{~min}$ ).

\section{Discussion}

Isolated human PMNL responded to particulate and soluble stimuli with a sequential release of specific and azurophilic granule proteins. Surprisingly, zymosan induced a concurrent discharge of elastase and lactoferrin although both proteins belong to different lysosomal populations. In contrast, extracellular release of myeloperoxidase and generation of $\mathrm{CL}$ was significantly retarded. The latter held also true for the response to endotoxin and might be a further indication that luminol- 

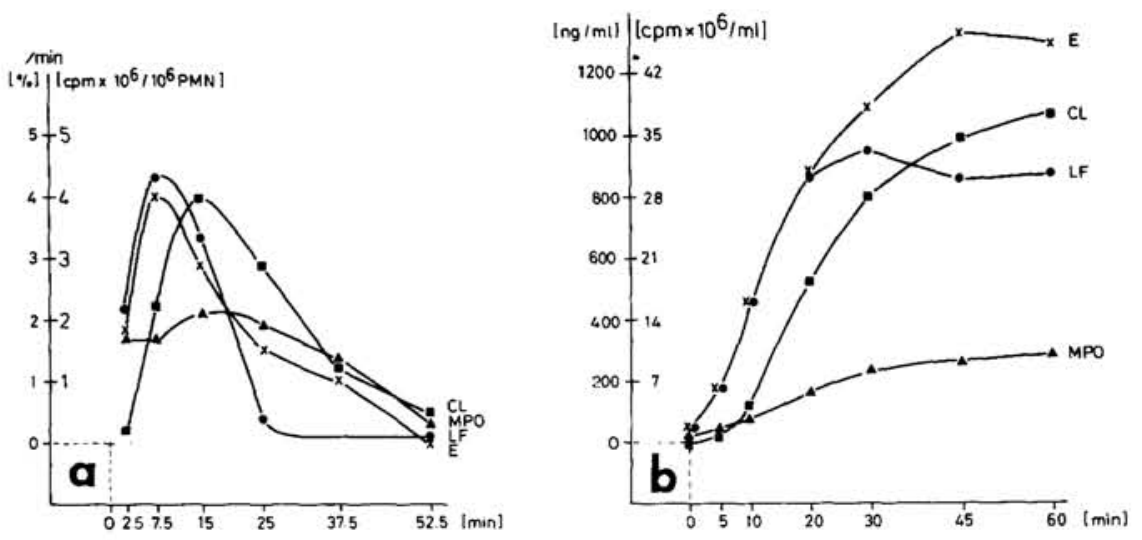

\section{Endotoxin}
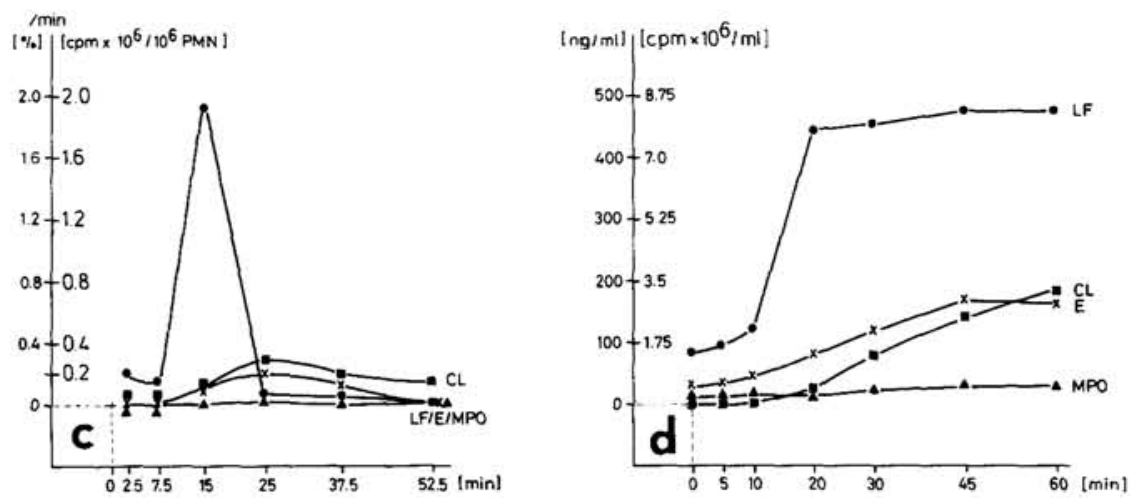

Fig. 1a-d. Release of elastase $(E)$, myeloperoxidase $(M P O)$, and lactoferrin $(L F)$ and chemiluminescence response $(C L)$ after stimulation of polymorphonuclear leukocytes with zymosan and endotoxin. a, c \% of total/ $\min (\mathrm{E}, \mathrm{MPO}, \mathrm{LF})$ and counts/min $(\mathrm{CL})$ per $10^{6} \mathrm{PMNL} ; \mathbf{b}, \mathbf{d} \mathrm{ng} / \mathrm{ml}(\mathrm{E}, \mathrm{MPO}, \mathrm{LF})$ and counts/min $\cdot \mathrm{ml}(\mathrm{CL})$

enhanced CL is totally dependent on the myeloperoxidase- $\mathrm{H}_{2} \mathrm{O}_{2}$ system [6].

The selective release of the specific granule content due to endotoxin stimulation may be correlated with the extracellular antibacterial role of lactoferrin in inflammatory processes [7].

In summary, the preliminary data indicate that the signals governing the release of lysosomal inflammation mediators may be specific for the individual protein rather than for the different types of granules as has hitherto been assumed.

\section{References}

1. Bentwood BJ, Henson PM (1980) J Immunol 124:855-862

2. Klebanoff SJ, Clark RA (1978) The neutrophil. NorthHolland Publishing $\mathrm{Co}$, Amsterdam
3. Fritz H, Jochum M, Duswald KH, Dittmer H, Kortmann H, Neumann S, Lang H (1984) In: Goldberg DM, Werner M (eds) Selected topics in clinical enzymology, vol 2, Walter de Gruyter \& Co, Berlin New York, pp 305-328

4. Allen RC, Stjernholm RL, Steele RH (1972) Biochem Biophys Res Commun 47:679-684

5. Dwenger A, Schweitzer G, Regel G (1986) J Clin Chem Clin Biochem 24:73-88

6. Dahlgren C, Stendahl O (1983) Infect Immun 39:736-741

7. Hansen NE, Karle H, Andersen V, Malmquist J, Hoff GE (1976) Clin Exp Immunol 26:463-468 